\title{
Stage IIIA Uveal Melanoma AJCC v7
}

National Cancer Institute

\section{Source}

National Cancer Institute. Stage IIIA Uveal Melanoma A/CC V7. NCI Thesaurus. Code C88137.

Stage IIIA includes: (T2c-d, NO, M0); (T3b-c, NO, M0); (T4a, NO, MO). T2c: Ciliary body and choroid: Tumor size category 2 without ciliary body involvement but with extraocular extension less than or equal to $5 \mathrm{~mm}$ in diameter. T2d: Ciliary body and choroid: Tumor size category 2 with ciliary body involvement and extraocular extension less than or equal to $5 \mathrm{~mm}$ in diameter. T3b: Ciliary body and choroid: T umor size category 3 with ciliary body involvement. T3c: Ciliary body and choroid: Tumor size category 3 without ciliary body involvement but with extraocular extension less than or equal to $5 \mathrm{~mm}$ in diameter. T4a: Iris: T umor with extrascleral extension less than or equal to $5 \mathrm{~mm}$ in diameter. Ciliary body and choroid: Tumor size category 4 without ciliary body involvement and extraocular extension. N0: No regional lymph node metastasis. M0: No distant metastasis. (AJCC 7th ed.) 